\title{
Of technical writing, instructions for use as a specialised genre and discourse communities
}

De la rédaction technique, des modes d'emploi en tant que genre spécialisé et des communautés discursives

Shaeda Isani

\section{OpenEdition}

\section{Journals}

Electronic version

URL: http://journals.openedition.org/asp/5713

DOI: 10.4000/asp.5713

ISSN: 2108-6354

Publisher

Groupe d'étude et de recherche en anglais de spécialité

Printed version

Date of publication: 2 March 2019

Number of pages: 3-23

ISSN: 1246-8185

\section{Electronic reference}

Shaeda Isani, « Of technical writing, instructions for use as a specialised genre and discourse communities », ASp [Online], 75 | 2019, Online since 02 March 2020, connection on 02 November 2020. URL : http://journals.openedition.org/asp/5713; DOI : https://doi.org/10.4000/asp.5713

This text was automatically generated on 2 November 2020

Tous droits réservés 


\title{
Of technical writing, instructions for use as a specialised genre and discourse communities
}

\author{
De la rédaction technique, des modes d'emploi en tant que genre spécialisé et des \\ communautés discursives
}

Shaeda Isani

1 Technical instructions are an ancient genre, one of the oldest examples of which may be instructions engraved on a Sumerian cuneiform tablet dating back to $4000 \mathrm{BC}$ concerning the making and applying of poultices (Swales 1997). For Svenvold (2015), another early example of the user manual is De architectura by the 1st century BC Roman author, architect, civil and military engineer, Vitruvius. If De architectura was more a compendium than a user manual, Moxon's Mechanik Exercises, a guide to printing published in the late 17th century was a manual which provided "systematic treatments for solving complex problems" and "rang with a decidedly DIY tone" (ibid.). For Basquin (1981), a writer of technical manuals, Chaucer's Treatise on the Astrolobe written in the 15th century qualifies him as the first technical writer in English. Schumacher (2018), citing Bridgman, former curator at London's Science Museum, indicates the pamphlet "Directions for using the Patent Portable Copying Machine Invented and Made by James Watt \& Co." published by James Watt in 1795 on how to use the desktop office copier he had just invented, as one of the earliest examples of instructions for use as we understand the genre today.

2 Far from being the frustratingly tedious texts they are seen as today, for Svenvold, these early manuals heralded an important turning point in the socio-professional organisation of the epoch:

They suggested that readers could learn a new trade, at home, in their spare time. To someone in 17th century Europe, this was a deeply subversive notion. From the fall of the Roman Empire to the dawn of the Renaissance, age-old social hierarchies held firm. [...] But then came science and technology, and with them, new trades and opportunities. With no established guild system in place for many of these new 
professions (printer, navigator, and so on), readers could, with the help of a manual, circumvent years of apprenticeship and change the course of their lives [...]. These books, filled with ingenuous methods, offered something new and relatively democratic: agency, skill, and command for anyone who could read. (Svenvold 2015)

With the democratisation and increased technicity of consumer household products during the 20th century, manuals grew in number, size and complexity as exemplified by the bulky user manuals which accompanied electronic products during the 1970s and 1980s.

4 This study is based on over a quarter of a century's experience first in translating and producing technical texts in the field of high-voltage transmission and then in teaching procedural writing for a Master's course on translating and producing technical texts in English. ${ }^{1}$ For reasons of pedagogic efficacy (authentic documents, graded degrees of technical difficulty and specialism diversity) and practicality (short, low-tech texts), a collection ${ }^{2}$ of over a hundred non-dematerialised written instructions for use related to relatively non-specialised consumer products - from toasters to sump pumps, with lawn mowers, car radios, paint guns, food slicers, shower curtains, etc., in between was compiled between 1993 and 2014.

5 Most texts, notably those in the form of a booklet, provide translations. The 47-page $21 \mathrm{~cm} \times 15 \mathrm{~cm}$ booklet accompanying the Kärcher power hose, for example, is in German, Italian, Portuguese, English, Dutch, Danish, French, Spanish and Norwegian. Others also provide Arabic and Chinese translations. Regarding English, if documents accompanying goods manufactured in the UK or the USA may be assumed to have been drafted in English, those accompanying goods manufactured in other countries are likely to have been translated into English or produced by non-native drafters. ${ }^{3}$

\section{Procedural texts: an umbrella genre}

6 Procedural texts, an essentially written genre, are instructional texts which "explain how to realize a certain goal by means of actions which are at least partially temporally organized" (Aouladomar \& Saint-Dizier 2005; also see Coutherut 2017) or, more explicitly, "[A] procedural text is a sequence of sentences describing instructions to create an object or to change an object into a certain state" (Maeta et al. 2015). Procedural texts permeate both professional and non-professional life since the genre ranges from "apparently simple cooking recipes to large maintenance manuals. They also include documents as diverse as teaching texts, medical notices, do-it-yourself notices, itinerary guides, advice texts, savoir-faire texts, etc." (Saint-Dizier et al. 2014). For Ramaker (2007: 2), even e-mailing directions to a destination qualifies as procedural writing.

7 Aouladomar and Saint-Dizier (2005), citing J. M. Adam's work on the classification of procedural texts, highlight the diversity of the genre by proposing seven categories: regulatory (describing expected behaviour); procedural (linear sets of instructions); programmatory (which include recipes and even musical scores); instructionalprescriptive (concerning detailed analysis of event and temporal structures); injunctive (indicating form and style to be used in short notices - fire instructions, security measures - or style guides); advice (such as found in general circulation magazines); and finally, recipes. As a result, the scope of products covered by procedural texts is 
wide and heterogeneous, covering consumer products such as toys, microwave ovens, lawn mowers, etc., on the one hand, and industrial products such as extractors, forklifts, jack-hammers, etc., on the other. Given this extensive range, procedural texts unsurprisingly encompass a variety of subgenres according to technicity and length, resulting in a medley of overlapping terms: user manuals, user handbooks, user guides, owner's manuals, service manuals, directions for use, instructions for use, operating instructions, etc. Frutos (2015), overriding potential terminological incongruities, suggests that whether "a leaflet or an 80-page book" (2015: 103), the term "manual" should be retained as a generic term for all procedural texts. The collection of texts used for the purposes of this study being composed essentially of single A4s or folding leaflets, the term "manual," connotative as it is of a lengthy text whether book, CD or DVD, goes against the grain of our linguist's sensibilities. As such, we choose to identify the texts related essentially to household appliances and everyday consumer products as instructions for use (IFU henceforth), esteeming focus on shared content and linguistic characteristics a more accurate generic identifier than a possibly mismatched form.

An IFU, also known as "a technical communication document" or "product documentation," describes correct usage, care and repair-related advice (troubleshooting) concerning the product it accompanies. Even if Ramaker sees "a symbiotic relationship [...] between the product and its technical manual" (2007: 10), she admits that it is often perceived as "an afterthought or footnote to the product and packaging" (ibid.: 9). It is, nevertheless, a legally binding document which is considered to be part of the product itself and is mandatory for the CE marking ${ }^{4}$ required for products placed on EU or EEA markets. Furthermore, EU Resolution C411 (Council of Europe 1998) stipulates that manufacturers must provide user documentation in the user's own language ${ }^{5}$ and, should the translation contain errors preventing the user from using the product or using it safely, the product itself is to be considered defective and recalled. Injuries and/or loss due to mistranslation incur the liability of the manufacturer and distributor. ${ }^{6}$

9 To conclude on this point, procedural texts like IFUs have underlying functions beyond simply instructing users on how to assemble, install or use products. Behind every IFU, there is a customer and, as Ramaker points out (2007: 2), IFUs are an indirect form of advertising for the manufacturer since a well-written IFU not only provides instructions but also furthers customer satisfaction, brand loyalty, product accessory purchases, product upgrades and reduced technical support calls and product returns all of which are reflected in the content elements and rhetorical moves of IFUs.

\section{Textual features of IFUs: content organisation and rhetorical moves}

10 If user manuals can run to several hundred pages - monolingual 600-page computer manuals were not uncommon in the 1980 s -, in the context of IFUs accompanying runof-the-mill everyday consumer products, the documents generally vary from between an A4 to a small booklet. This conforms to both the manufacturer's need to economise on drafter's fees, paper and printing expenses, and the end-user's desire for a short and simple text. Far from being inconsequential, this textual constraint may also be responsible for the distinctively condensed style and register of the genre, as we shall see later. 
11 Procedural texts bring into play complex content and rhetorical moves as analysed by researchers at the IRIT-CNRS in Toulon (Aouladomar \& Saint-Dizier 2005; Fontan \& StDizier 2008) who classify them into core and annexe moves. IFUs present simpler content organisation on account of the relatively low-tech nature of the products and limited length of the text. In spite of inevitable variations, content elements in IFUs follow a quasi-formulaic template.

\subsection{Self-promotional discourse}

12 IFUs generally begin with an introductory word of self-praise, of which the following extract provides an illustrative example:

Congratulations for choosing the OREGON SCIENTIFIC electronic calculator-travel alarm clock. As with all OREGON SCIENTIFIC products, this calculator-travel alarm clock is made to highest quality standards and uses high precision electronic components.

\subsection{Guarantee information}

13 Since the shift from buyer responsibility (caveat emptor) to seller responsibility (caveat venditor) in the 1960s, the seller is required to respect buyers' statutory rights, one of the most salient of which is product guarantee. In the context of IFUs, guarantee information can run from a few token lines to a few paragraphs. It is generally placed either right after the promotional move or at the end of the text. The following is representative of the type of perfunctory guarantee information frequent in IFUs:

This Black and Decker table vacuum cleaner is guaranteed for a period of one year (filter not included). In case of malfunction, contact nearest Black \& Decker after sales agent.

Guarantee information puts the drafter in an ambivalent position: while purporting to reassure buyers of the company's trustworthiness, in a rhetorical move no doubt intended to discourage customer claims, it also flags restrictions through the multiplication of provisos and use of implicit but nevertheless intimidating legalese, as the following extract demonstrates:

[Carrefour TopBikes] are guaranteed free from manufacturing defects for two years, including parts and labour, and five years on frames, starting from date of purchase and upon presentation of cash receipt. This warranty is limited to the repair or replacement at no charge of parts that are found to be defective by our certified technician.

Procedures carried out under this warranty do not result in the warranty being extended.

This warranty is subject to the following conditions:

1. That the bicycle has been repaired by a certified professional.

2. That the bicycle has not been modified or altered.

3. That the original parts have not been replaced by others that are not certified by the manufacturer.

4. That the damage is not due to lack of maintenance, negligence or lack of experience on the part of the user, abnormal use, incorrect adjustments, defective repair, or temporary overloading.

5. That the damage is not due to the normal wear and tear of the equipment such as: tyres, electrical bulb, chains, remote operating cables, brake pads, front lamp lenses and rear lamp tailpieces, derailleurs and free wheels. 


\subsection{Injunctive discourse} classic do's and don'ts on how to proceed with the assembly, installation or use of the product. Often accompanied by diagrams, these are expressed through the imperative tense and modals of obligation to underline the deontic aspect of the rhetoric:

Install unit in well ventilated room with room temperatures between $+16^{\circ} \mathrm{C}$ and

$32^{\circ} \mathrm{C}$.

Mains power connection must comply with NF C15-100.

Do not place freezer near source of heat.

To prevent ice formation, do not leave door open for prolonged periods.

(Liebherr freezer-fridge)

The following extract regarding what is basically a simple-to-use cooking utensil commercialised by a well-known American brand carries the language and graphics of the warning rhetorical move to a quasi-caricatured degree, no doubt a consequence of the renowned product liability laws and litigation-prone culture of the country:

GLASS-CERAMIC CORNINGWARE ${ }^{\circledR}$ \& VISIONS $^{\oplus}$ PRODUCTS $^{2}$

READ and SAVE these instructions.

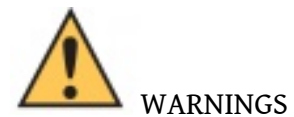

ALWAYS USE POTHOLDERS WHEN HANDLING HOT COOKWARE.

DO NOT place HOT cookware on counter. Use protective trivet.

DO NOT place cover on any rangetop burner, under a broiler, microwave browning

elements, in toaster oven or oven vent or pilot light.

NEVER place HOT cover in sink or on cold or wet surfaces. Handle with dry potholders.

DO NOT strike utensils against rim to dislodge food.

DO NOT use glass ceramic cookware to pop corn, caramelize sugar, make candy or deep fry.

DO NOT use abrasive cleaners, scouring pads, or any object that will scratch the cookware or covers.

DO NOT use or repair any item that is chipped, cracked or broken.

DO NOT use accessories in oven or microwave, under broiler, or on top of stove unless otherwise indicated.

Commonsense safety measures were previously taken-for-granted in obvious everyday situations. IFUs did not need to warn customers to not insert sharp knives into their mouths, for example. In the event of a more technical product, safety warnings were generally integrated within the body of the injunctive section of the IFU, e.g. "Disconnect unit from mains before proceeding." However, the growing threat of litigation and the obligation in many countries to include health and safety guidelines has led manufacturers to protect their liability by featuring safety as a separate section in IFUs, notably in the case of more complex products, as Kärcher, for example, who devote two out of six pages of the English section of the IFU accompanying their power hose to "Safety Instructions".

\subsection{Trouble-shooting or repair-related recommendations}

Trouble-shooting or repair-related recommendations concern advice intended to save the owner time, trouble and money. Illocutionary rather than deontic, if these 
rhetorical moves do indeed make use of the imperative tense intrinsic to operating instructions, they tend to eschew modal verbs of obligation:

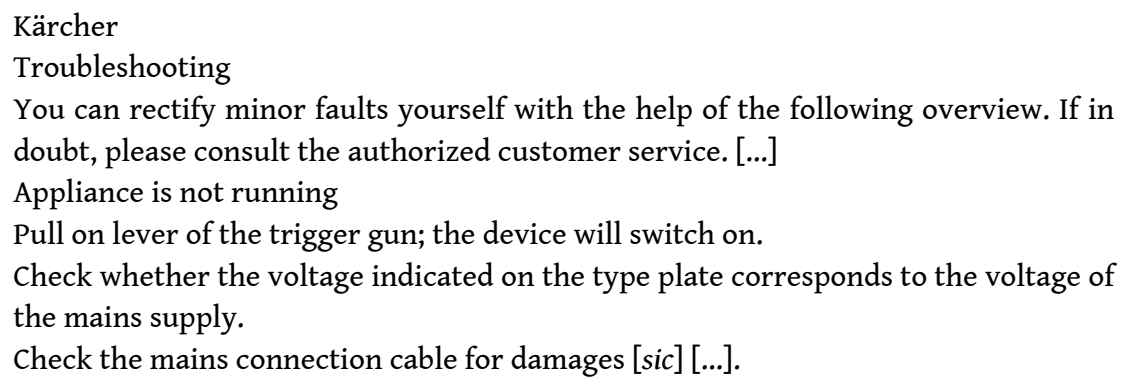

\subsection{Information regarding after-sales}

Information regarding after-sales is another recurrent feature of IFUs. However, given the worldwide distribution of consumer products, such information tends to be vague, often reduced to a token phrase, e.g. "In case of breakdown or malfunction, contact nearest XXX customer service."

One exception is the after-sales contact information for the Dyson Hot + Cool Jet Focus Fan Heater which multiples options to an extent which may prove to be timeconsuming and, in the end, futile, for the average customer:

DYSON CUSTOMER CARE THANK YOU FOR CHOOSING TO BUY A DYSON APPLIANCE. After registering your free 2 year guarantee, your Dyson appliance will be covered for parts and labour for 2 years from the date of purchase, subject to the terms of the guarantee. If you have any questions about your Dyson appliance, call the Dyson Helpline with your serial number and details of where/when you bought the appliance. Most questions can be solved over the phone by one of our trained Dyson Helpline staff. Your serial number can be found on your rating plate which is on the base of the appliance. Visit www.dyson.co.uk/support (UK) or www.dyson.ie/ support (ROI) for online help, support videos, general tips and useful information about Dyson.

To conclude on this section, we would like to draw attention to the growing presence of a relatively new feature in IFUs. Owing to environmental concerns, in particular those related to mass consumerism, companies increasingly include a section on the "green" disposal of the product in their IFUs. No doubt an endeavour to "greenwash" their corporate image, there is often a distinctly self-promotional overtone, as seen in the following extract:

It is easy to return and recycle your HP LaserJet print cartridges after use - free of charge - with HP Planet Partners. Simple return instructions are provided in this guide. You help reduce the toll on the environment further when you return your multiple cartridges together rather than separately.

HP is committed to providing inventive, high-quality products and services that are environmentally sound, from product design and manufacturing to distribution, customer use and recycling. When you participate in the HP Planet Partners program, we ensure your HP LaserJet print cartridges are recycled properly, processing them to recover plastics and metals for new products and diverting millions of kilograms of waste from landfills. 


\section{Linguistic features of IFUs: of brachyology and asyndetons} drafters advertising their services abound on the net. For non-professionals, there is a host of on- and offline style guides on technical writing as, for example, the academic BIOSYSTEMS Engineering Technical Writing Guide published by Michigan State University (2007) or the corporate IBM Style Guide (DeRespinis et al. 2012). These detail the conventions of the genre regarding linguistic style, register, layout, formatting and even appropriate attitudes to be adopted by would-be writers of IFUs. Most of the advice concurs. Indeed, who could possibly take issue with the recurrent advice "keep it short, keep it compact, keep it simple" (Weinburger et al. 2015). Regarding the actual linguistics involved, though all technical/scientific style guides agree on the use of the simple present tense, the imperative mood and the active voice, variations inevitably exist. Linguistic features commonly recommended can nevertheless be summed up into 12 sometimes overlapping do's and don'ts:

1. Avoid wordiness ("clean filter on a daily basis" => "clean filter daily").

2. Terminology must be consistent throughout.

3. Avoid "technicalese". Use standard words (i.e. "plain words") which are commonly used and hence familiar to consumers.

4. Use the present tense, active voice and instructive mode (imperatives).

5. Avoid deictics: personal pronouns, whether first, second or third persons, "this" and "it" unless antecedents are clearly indicated.

6. Avoid phrasal verbs.

7. Avoid overuse of the definite article "the". As Precision Science Editing, a company specialising in editing for scientists, recommends, "definite articles, like salt, are at their best when used sparingly".

8. Avoid modal auxiliaries such as would, should, could, may and might as they vector a degree of uncertainty.

9. Avoid contractions (can't, won't, don't, aren't) to maintain a formal register of English.

10. Avoid colloquialisms and clichés.

11. Avoid gender-neutral language: no "his/her", or "s/he"; no neologisms like "personhole" for manhole, "person hours" for man hours or "person power" for manpower.

12. Avoid abbreviations and acronyms. 
As evidenced in our Master's classes year after year, native- and non-native technical writers and translators are understandably reluctant to adopt a form of non-Standard English which so egregiously contravenes the most basic rules of grammar. This dilemma is highlighted by the two extracts presented below: the first is a print version of an IFU written several years ago for a Swiss-manufactured shower curtain which represents state-of-the-art compliance with the "transgressive" conventions of IFUs; the second is a recent updated online version whose style conforms to Standard English norms and in so doing, breaches those of the genre, thus creating an unusual situation of hypercorrection:

Fig. 1. Comparison between Spirella shower curtain IFU c. 1990s and today

\begin{tabular}{|c|c|}
\hline $\begin{array}{l}\text { Print version } \\
\text { (c. 1990s) }\end{array}$ & $\begin{array}{l}\text { Online version today <www:spriella.ch/en/p/12/care-instructions> } \\
\text { Consulted } 02 / 10 / 2018\end{array}$ \\
\hline $\begin{array}{l}\text { Care } \\
\text { Machine wash regularly } \\
\text { with detergent and } \\
\text { fabric softener once a } \\
\text { month }\left(40^{\circ} \mathrm{C} / 104^{\circ} \mathrm{F} /\right. \\
\text { warm). } \\
\text { Rinse after use to } \\
\text { eliminate soap and } \\
\text { shampoo residue. } \\
\text { Hang and draw to dry. } \\
\text { In case of mould stains, } \\
\text { soak stained parts in } \\
\text { solution of } 10 \text { parts } \\
\text { lukewarm water and } 1 \\
\text { part household bleach } \\
\text { for } 15-20 \text { minutes. } \\
\text { Rinse thoroughly in cold } \\
\text { water. }\end{array}$ & $\begin{array}{l}\text { Daily care } \\
\text { Rinse off soap residues with warm water. Extend shower curtain to its } \\
\text { full width to dry. } \\
\text { Tips: How to remove mould stains } \\
\text { The warm and humid conditions in bathrooms are an ideal breeding } \\
\text { ground for mould. It is best prevented by regular ventilation. In case } \\
\text { of mould stains on the inside of the textile shower curtain, they are } \\
\text { easily removed with a weak chlorine solution: Rinse affected curtain } \\
\text { in chlorine for } 15-20 \text { minutes, moving it all the time. Wash chlorine } \\
\text { solution out with plenty of cold water. Wash with mild detergent and } \\
\text { with delicate cycle at } 40^{\circ} \mathrm{C} \text {. Hang up while still damp. }\end{array}$ \\
\hline
\end{tabular}

In view of the stylistic constraints imposed by genre conventions, the question arises as to whether IFUs are a form of controlled language, i.e. a subset of a natural language with artificially restricted vocabulary, grammar and style designed for technical information dissemination. Typically, it is a question of imposed simplified grammar rules and limited monosemous vocabulary ${ }^{7}$, the objective being to reduce ambiguity by cultivating consistency of language and so simplify comprehension for non-specialists and non-native speakers of English, and facilitate machine translation.

Controlled languages are most often elaborated by large multinational companies. In this respect, Caterpillar Fundamental English (CFE) is a pioneering example. Designed in the 1970s by Caterpillar, a heavy equipment manufacturing company, the aim was to provide a common language for its 20,000 technical publications that needed to be understood by over 10,000 dealer service staff who spoke 50 different native languages. 
The CFE lexical range was reduced to 800 words and syntax grounded in ten very general rules of basic good communication ${ }^{8}$.

How does a genre like IFUs concerning basic consumer goods relate to controlled languages? Though references to controlled language have been cited in connection with IFUs, judging by the samples studied, it is not a major preoccupation. The reason is most certainly related to the immense diversity of products and customers, small volumes of scale (instructions for use are essentially a one-off per product), and the absence of significant stakes. Corporate operating manuals, service guides and maintenance handbooks, on the other hand, target specific technical areas and readers, in addition to which the documents can run to several hundred pages (now usually digital) and need to be constantly updated, all factors justifying investment in a controlled language.

Today we observe a certain evolution of the genre towards Standard English. This is no doubt due to improved machine translation mediation and better qualified translators and revisers. Hence the genre is currently witnessing a period of instability in which the conventional "deviant" style is sandwiched between raw unmediated machine translations on the one hand, and Standard English on the other, as illustrated by the following extract from an IFU for a food slicer commercialised circa 2014 by Ritter, a German manufacturer:
A. Setting-up the appliance
Set the appliance down on a flat, non-skid surface close to a mains socket.
B. Remove the left-over holder (12) and then the finger protection (11) from the appliance and lift out the tray (5).
C. Unwind the mains cable (14) to the length required from the cable compartment (7) under the appliance. In doing so, fasten the mains cable in the slot provided for it on the base of the appliance.
D. Swivel the slice cartridge (10) into the working position.
E. Using a small amount of force, push the finger protection into the opening on the slice carriage, and slide it in the direction of the stop plate (2) until you hear it lock into place.
F. Slot the left-over holder into place on top of the finger protection.
G. Plug the cable into the socket.

We cannot conclude on the linguistic characteristics of the IFU as a genre without addressing one of the foundational notions of specialised genres, that of specialised lexis (Swales 1990). Given the extensive variety of products covered by the genre, specialised lexis is a shifting variable which ranges from highly technical to relatively simple according to the nature of the product, as we see in the two extracts in Figure 2.

Fig. 2. Specialised lexis: from very technical to relatively simple

\begin{tabular}{|l|l|}
\hline Ikea electric screwdriver & Alcatel Temporis landline telephone \\
\hline $\begin{array}{l}\text { This basic cordless screwdriver } \\
\text { will accept various types and } \\
\text { length of screwdriver bits that } \\
\text { have a hexagonal shank that is } \\
6.35 \mathrm{~mm}(1 / 4 ") \text { across the flats. }\end{array}$ & $\begin{array}{l}\text { Wall mounting: Turn over the wall mounting peg (small } \\
\text { grooved plastic part) on the base using a coin. Drill two } 6 \mathrm{~mm} \\
\text { holes } 100 \mathrm{~mm} \text { apart. Fit two wall plugs and screw in wood } \\
\text { screws }(3.5 \mathrm{~mm} \text { in diameter and } 30 \mathrm{~mm} \text { long). Mount the base } \\
\text { on the two screws by pulling it downwards. Take out the foot } \\
\text { stand and re-install it in the wall mount location. }\end{array}$ \\
\hline
\end{tabular}


Specialised lexis remains a moot point concerning the IFU genre, split as it is between its essential technicity on the one hand and the injunction to avoid "technicalese" on the other. One explanation for this contradiction lies in the profile of the addressee, as seen in the following section.

\section{IFUs as a specialised genre: a discourse community?}

The highly conventionalised syntactic features of IFUs mark them out as a specialised genre, as confirmed by Bhatia's definition (albeit applied to disciplinary or social institutions):

Genre essentially refers to language use in a conventionalised communicative setting in order to give expression to a specific set of communicative goals [...], which gave rise to stable forms by imposing constraints on the use of lexicogrammatical and well as discoursal resources. (2004: 23)

But specialised genres are not created ex nihilo nor do they exist in in vitro vacuums. They are born, live, flourish, evolve and even die in keeping with the specific sociopragmatic and social environments (Bhatia, ibid.) which create and nurture them hence the importance of the addresser/addressee parameter in genre studies.

It is unquestionably Swales's Genre Analysis (1990) which foregrounded the concept of discourse community in ESP studies. Summed up briefly, the Swalesian concept revolves around the notions of a group of people with shared public goals and mechanisms of intercommunication which facilitate information and feedback, the existence of genres and specialised lexis to further these aims and "a threshold of members with a suitable degree of relevant content and discoursal expertise" (1990: 29). In 2016 Swales revisited his 1990 definition in light of the phenomena of globalisation, computers and social media, enhancing it with the notions of "local discourse communities" (groupings of people working at the same place or occupation in the same area), focal discourse communities (associations reaching across a region, a nation, the world), and "folocal discourse communities" (members with dual or split allegiances). However, whatever the nuances brought to the original concept of discourse community, a number of fundamental criteria - specialised lexis and syntax, the notion of members sharing more or less the same degree of expertise - remain stable. As such, we propose to investigate the notion of discourse community and the all-important question of "members" in relation to IFUs by looking at the two stakeholders most concerned by the rhetorical text-addresser-addressee triangle, i.e. addressers (technical writers) and addressees (end-users).

\subsection{Addressers: IFU technical writers}

In this era of job-title inflation, writers of technical texts are known as "technical communicators," "information architects," "usability engineers" or "information developers" (Ramaker 2007: 4). Whatever the title, the point that retains our interest is the profile of the drafter.

The following position for a technical writer advertised online by Siemens Healthineers located in Issaquah, WA. provides a job description and outlines the profile sought: 
Technical Writer 2

Locations: Issaquah, Washington

Job Family: Communications

Job Description

Division: Siemens Healthineers

Business Unit: Ultrasound

Requisition Number: 232757

Primary Location: United States-Washington-Issaquah

Assignment Category: Full-time regular

Experience Level: Mid level

Education Required Level: Bachelor's Degree

Travel Required: $5 \%$

Job Description:

Day in Life

- Effectively plan, design, research, write, edit, publish, and release information products with a focus on a global audience, primarily user manuals for medical devices, including operational, instructional, or maintenance procedures for paper, multimedia, web-based publications and user sites; may produce content for embedded user assistance technology.

- Manage multiple, simultaneous projects and proactively communicate status with internal and external stakeholders, including translation and publication vendors.

- Create formats responsive to technical and customer requirements.

- Understand how regulations, laws, and standards influence content design.

- Understand the impact of localization on English content.

- Create and maintain design documentation to support quality assurance and regulatory standards, while contributing to process innovations.

- Collaborate openly and effectively with a range of stakeholders, including writers and subject matter experts.

- Take direction to be able to work as a team and independently, making sound, process- and customerdriven decisions.

- Express ideas clearly and diplomatically.

- Give and receive constructive feedback.

- Successfully negotiate project schedules, plans, and milestones as a representative of the tech writing team

- Minimum Qualifications

- B.S./B.A. in technical communications, writing/composition, or similar related field

-2+ years of experience with Bachelor's degree

- Technical writing experience with user manuals for a global audience

- Experience delivering solutions with a cross-functional project team

- Knowledge of tools and technologies used for writing, publishing, and document control

- Experience working with translation suppliers and formatting teams for creating multi-language documents and regional representatives for preferred terminology

- Nice to Have:

- Prior experience in all phases of developing and delivering user manuals for a medical device in a regulated industry in multiple languages

- Excellent problem-solving skills

- Strong attention to detail and accuracy

- Ability to learn and adapt to changes in technology, processes, and requirements

- Ability to work effectively across disciplines and international boundaries to implement creative solutions to complex problems

- Knowledge of Siemens Healthineers products and quality system

- Understand industry trends in technical communication, information architecture, and content development ${ }^{9}$

(<https://jobs.siemens-info.com/jobs/232757/Technical-Writer-2?lang=en-

us\&src=JB-10066>. Consulted 21/10/2018)

Positions for such high-profile technical writers generally exist only in the context of multinational firms whose volumes of scale justify a dedicated position. We nevertheless note that the duties outlined extend well beyond the actual drafting of technical documents to include ancillary services ranging from public relations to knowledge of the legal context. What is particularly noteworthy here - and a recurrent 
feature in similar positions examined - is that, contrary to expectations, while a relevant university degree in language and communication skills is classified as a minimum qualification requirement, specialism knowledge is only "nice to have."

It is doubtful whether IFUs that accompany run-of-the-mill consumer products are drafted by dedicated in-house technical writers or out-sourced to professionals. The person behind the IFU is most likely to be the engineer, technician, product or project manager overseeing the manufacturing of the product (all of whom, we note in passing, have the specialism knowledge but not necessarily the language competence) and whose work may or may not be submitted for revision to local in-house native speakers or outside professionals.

One of the striking singularities of the technical writer's profession is its anonymity. IFUs, like most procedural texts, are unsigned, their authors unnamed. Author anonymity is embedded in the very conventions of the genre which neutralises author positioning by abjuring the use of personal pronouns as 'I' or 'We' (Aouladomar \& Saint-Dizier 2005). Namelessness is not new to the genre as evinced by a survey on problems experienced by technical writers carried out by the Rensselaer Polytechnic Institute (New York) in the early 1960s in which Gould reports that among the problems evoked by technical writers surveyed at that time was that "they get tired of their anonymous existence" (1963: 13), a phenomenon he attributes to the multiple hands and convoluted process the technical text goes through:

In many places, the pride of authorship has been all but lost. The engineer or scientist is asked to report his activities. The report is then passed on to a supervisor who suddenly becomes an editor. Somewhere along the line, a professional editor-the technical writer-does a job on it. It goes back to the original writer for revision. Eventually, it lands on an executive desk for more revisions. In its final form, the report does not bear the name of the original author, nor does he recognize it as having come from him. In some cases, perhaps, it is impossible to attach the name of the writer. However, most people like to see their efforts in print and to be acknowledged as the authors. (1963: 13)

According to Ramaker, however, masking author identity serves promotional purposes in that it highlights that of the company's:

The technical writing genre constrains and limits authors' attempts to cultivate a relationship between themselves and the audience. The best example of this is the fact that most technical manuals do not readily attribute the writing to any specific person or group. [...] The product name is emphasized most and is usually accompanied by an image of the product, closely followed by or matched in size by the company name and logo. These names are what sell the product and what audiences look for. (Ibid.: 4)

Another characteristic of the function is the inherent dilemma regarding the technical writer's divided loyalties evoked earlier: on the one hand, there is the paymaster, the person who commissions the work; on the other, there is the person for whom the text is written, the end customer, but with whom the author has no contact. The interests of the two parties may not coincide. In the case of legal aspects like guarantees, disclaimers and warnings, for example, do technical writers highlight customers' rights and so encourage claims in case of design defect, malfunction, breakdown or even personal injury? Or do they orient the text in the seller's favour by accentuating manufacturers' rights and buyers' obligations to discourage such claims? The latter is quite possible as the daunting safety instructions relative to the Ritter food slicer suggest: 
General Safety Instructions

To avoid personal injury or damage to the appliance, please observe the following safety instructions:

1. The multi slicer is to be used for domestic purposes only and must not be used commercially.

2. Never set the appliance down on hot surfaces or close to naked flame.

3. Use the accessories included in the delivery specification only.

4. Use suitable extension cables only.

5. Do not bend the mains cables. Never wrap the cable around the appliance.

6. Route the mains cable so that it does not come into contact with hot or sharp-edged objects.

7. Only start to use the appliance after it has been securely set up.

8. Persons with reduced physical, sensory or intellectual capabilities or lacking in relevant experience and/or knowledge may only use this appliance if they do so under supervision or have been instructed in the safe use of the appliance and understand the potential risks associated with its use.

9. Do not allow children to play with the appliance.

10. Always disconnect the appliance from the mains whenever it is to be left unsupervised, and also prior to assembly, dismantling and cleaning.

11. This appliance must not be used by children. Keep the appliance and its connection cable out of reach of children.

12. Only connect the appliance to a suitable AC power source that complies with the specifications on the type label.

13. Never leave the appliance unattended while it is operating.

14. Do not use it to cut frozen foods, bones, food containing large stones, roast meats that are encased in netting or packaged foods!

15. Never allow the appliance to run for more than 5 minutes at a time.

16. If you wear a pacemaker or implanted defibrillator, you must keep a sufficient distance away from magnets.

17. Keep magnetic data carriers (credit cards, memory cards etc.) and electronic devices (mobile phones, computers, monitors etc.) away from strong magnetic fields.

While some of the warnings are perfectly justified in view of the hazards intrinsic to all cutting devices, item 8 appears particularly dissuasive regarding potential customer claims ("intellectual capabilities", "lacking in relevant experience", "under supervision", etc.) while items 16 and 17, totally irrelevant in the context, seem to stem from cut and paste procedures applied to all the firm's products to protect the manufacturer's liability. Did the technical writer's bias in favour of he who pays the piper cloud all discernment when drafting this particular section of the IFU?

\subsection{Addressees: product end-users}

According to Ramaker (2007), technical documents address three principal audiences, a primary audience (the users of the product), a secondary audience (the client who commissions the work and for whom it represents multiple ancillary objectives liability protection, promotion, reduced work for the helpdesk, etc. - in addition to informing the user), and finally, a tertiary audience (potential clients who consult IFUs before deciding on purchase) and competitors (who evaluate their own products in comparison). To this we add a fourth category, that of translators, who, as seen in the Siemens job offer, are one of the technical writer's main interlocutors. Our interest here lies with the primary audience, the end-user.

Guides to procedural writing invariably commence by the tenet that the technical writer's first task is to identify the target reader. In the case of manuals related to highly technical equipment or software, this is a relatively easy task in that the 
situation closely resembles that of peer-to-peer exchanges possible when there is "a threshold of members with a suitable degree of relevant content and discoursal expertise" (Swales1990: 29). On the other hand, the notion of a homogenous target audience becomes inoperable with regard to IFUs and the countless highly diversified end-users scattered the world over who are not domain-specialists or native speakers of English and whose interest for the genre is casual, transitory and often fraught with frustration.

As mentioned earlier, despite international regulations stipulating that IFUs must be translated into the language of the country of sale, this is not always the case and IFUs written only in English can be found. In this context, Kachru's (1992) categorisation of speakers of English into three concentric circles - the Inner circle (native speakers of English, e.g. UK, USA), the Outer circle (English as a second language, e.g. India, Nigeria) and the Expanding circle (English as a foreign language and professional lingua franca e.g. China, Russia, Brazil) - helps gauge the extremely complex profile of IFU readers with regard to the English language. The complexity of the situation is further increased when bearing in mind that there is a fourth circle which is situated out of the Kachruvian circles, i.e. people who speak no English at all! In spite of the muchdiscussed spread of English urbi et orbi, there are pockets of people all over the world including France, judging by personal experience - who are speakers of no English at all but are, nonetheless, purchasers of consumer products and as such, completely flummoxed by IFUs written only in English. IBM makes explicit reference to the heterogeneous nature of the English language competence of its public in the IBM Style Guide by specifying that

[T]he audience for IBM information includes native English-speaking users, users whose primary language is not English, and users who do not read or speak English but, instead, rely on information that was translated from English into another language. (DeRespinis et al. 2012: 235)

The disparate and shifting language, educational, technical and cultural profiles of IFU addressees makes for "nebulous communities" (Borg 2003: 399), a concept far removed from the notion of a discourse community in which experts address a target audience composed more or less of peers. ${ }^{10}$

Experienced IFU professionals are well aware of the linguistically and technically heterogeneous character of their target audience as evidenced by repeated injunctions to simplify the discourse and use plain words (no "technicalese") and simple syntax, eschew contractions, phrasal verbs, colloquialisms, slang, gender-neutrality, etc. Michigan State University's Biosystems Technical Writing Guide makes specific reference to non-native speakers of English when it directs technical writers to take into consideration "words that are a problem for the foreign reader" or use formal English because it is "explicit even for the foreign reader who uses English as a second language" (2007: 4). Similarly, chapter 8 of the IBM Style Guide (DeRespinis et al. 2012) is devoted to "Writing for diverse audiences", one category of which is identified as "the international audience."

This leads us to posit that, in the case of IFUs related to products designed for global distribution, technical writers must target the lowest common denominator as regards language competency, i.e. buyers with poor command of the language. Viewed in this perspective, IFUs represent a typical speech accommodation convergence strategy whereby fluent speakers of English (Kachru's Inner and Outer circles) simplify their 
normal language use to adapt to that of their presumed Expanding circle interlocutors, thus ensuring accessibility to a maximum number of consumers.

To conclude on this part, the discussion above highlights the somewhat paradoxical fact that if IFUs may indeed be considered a specialised genre on account of their specific textual and linguistic characteristics, the corollary notion of discourse community is more problematic: if the expert members (technical writers) do indeed exist (albeit anonymously), the ultra-diversified nature of IFU end-users makes it challenging to find a sufficiently unifying criterion allowing them to be regrouped under the banner of the same discourse community.

\section{Conclusion: future trends}

If the vast majority of everyday consumer products today continue to include paper documents, sweeping changes concerning both text and channel are already in motion.

Besides the language issue, in the context of the highly diversified global audience of IFUs, the written nature of the medium may be a barrier, thus explaining why inserting visuals alongside the text is systematically encouraged by style guides. However, a more radical response to the problem of written literacy is to simply do away with language and use only visuals instead. Ikea, the Swedish homeware giant, is a pioneer in the field of "wordless instructions" (Schumacher 2018). If the company's black and white pictograms and diagrams have both fans and detractors, the initiative nonetheless obtained international recognition by winning the 2015 Paul Mijksenaar Design for Function award.

Regarding the channel, even more radical changes lie ahead. The original paper leaflet or booklet and the later CD and DVD are all being pushed towards obsolescence by the digitisation of procedural texts. IFU information can now be found on digitised channels like dedicated websites, QR codes, internet FAQs, discussion forums, and crowdsourcing (cf. ifixit.com, "the free repair guide for everything, written by everyone"). YouTube is a widely popular channel in the field of "how-to" and in this respect, we note that a number of professional YouTube IFUs follow the wordless instructions trend as, for example, MacroBaby Store's YouTube demonstration of the Jané Muum Stroller which is crystal clear without there being a single spoken or written word throughout.

Another trend is user-generated online guides based on artificial intelligence (AI) which accelerates the process by anticipating user queries or predictively tracking keystrokes to navigate users away from problems. Augmented reality (AR) is also called into service: interactive manuals enable users to interact with the product as they learn to use it and smart glasses or "google glasses" enable them to see a diagram of the machine imposed on the machine itself and communicate problems directly to experts for remote assistance.

However, perhaps the most remarkable change regarding the channel concerns the fact that IFUs no longer "accompany" the product but are embedded within the product itself, as Svenvold (2015) indicates when he says "the manuals of old [...] have shapeshifted inwards, into the devices themselves." IFUs are now embedded in apps on smartphones and tablets, confirming the slogan "From paper binders to digital in your 
pocket" promoted by SwipeGuide, a consultancy specialising in digitisation of procedural texts.

Such radical changes in the subgenre of IFUs bring us back to the underlying question of global accessibility and the conclusion that barriers to access thrown up by the written medium and the English language, far from being attenuated by digitisation (however wordless), are likely to be reinforced by numerical illiteracy and the great digital divide that separates generations and cultures.

\section{BIBLIOGRAPHY}

ADAM, J.M. 2001. “Types de textes ou genres de discours? Comment classer les textes qui disent de et comment faire". Langages 141, 10-27.

AOULADOMAR, Farida \& Patrick SAINT-DIZIER. 2005. “Towards generating procedural texts: An exploration of their rhetorical and argumentative structure". Proceedings of the Tenth European Workshop on Natural Language Generation, June 2005, Ann Arbor. <http://acl.idc.upenn.edu/W/ WO5>. Consulted 15/10/2018.

BASQUIN, Edmond A. 1981. "The First Technical Writer in English: Geoffrey Chaucer". Technical Communication 28/3, 22-24. < https://www.jstor.org>. Consulted 16/10/2018.

BHATIA, Vijay K. 2004. Worlds of Written Discourse: A Genre-Based View. London: Continuum.

BORG, Erik. 2003. “Key concepts in ELT: Discourse Community”. ELT Journal 57/4, 398-400.

Council of Europe. 1998. "Council Resolution of 17 December 1998 on operating instructions for technical consumer goods". <https://eur-lex.europa.eu/legal-content/EN/TXT/? qid=1548946578050\&uri=CELEX:31998Y1231(02)>. Consulted 31/01/19.

COUTHERUT, Margaux. 2017. "L'électronicien francophone devant le manuel d'utilisation d'appareil rédigé et à rédiger en anglais”. ASp 71, 69-72.

CRABBE, Stephen. (Undated). "Controlled languages for technical writing and translation”. University of Portsmouth (UK). <http://www2.port.ac.uk/media/contacts-and-departments/ slas/events/tr09-crabbe.pdf>.

DERESPINIS Francis, Peter HAYWARD, Jana JENKINS, Amy LAIRD, Leslie MCDONALD \& Eric RADZINSKI. 2012. The IBM Style Guide: Conventions for Writers and Editors. Boston: IBM Press Pearson plc.

FONTAN, Lionel \& Patrick SAINT-DIZIER. 2008. "Analyzing the explanation structure of procedural texts". <www.semanticscholar.org>. Consulted 15/10/2018.

FRUTOS, Araceli Cristobalena. 2015. “A corpus-based genre study of instruction manuals for household appliances”. Procedia - Social and Behavioural Sciences 198, 103-111. Elsevier.

Glassdoor. 2018. “Technical writer salaries in Washington, région de États-Unis”. <https:// www.glassdoor.fr/Salaires/washington-dc-technical-writer-salaire-SRCH_IL. 0,13_IM911_K014,30.htm?countryRedirect=true>. Consulted 24/10/2018. 
Glossary of Rhetorical Terms. UK College of Arts and Sciences. <https://mcl.as.uky.edu/glossaryrhetorical-terms>. Consulted 12/10/2018.

GOULD, Jay, R. 1963. "Problems of the technical writer". STWP Review 10/4, 13-15. <http:// www.jstor.org>. Consulted 16/10/2018.

ISANI, Shaeda. 2017. "Of synaesthetic wine metaphors, discourse communities, addressers and addressees: the specialised language of wine descriptors”. ASp 72, 93-112.

KACHRU, Braj. 1992. "World Englishes: approaches, issues and resources”. Language Teaching 25, 114, Cambridge University Press.

KINGSCOTT, Geoffrey. 2002. “Technical translation and related disciplines”. Perspectives 10/4, 247255. DOI: 10.1080/0907676x.2002.9961449.

MAETA, Hirokuni, Tetsuro SASADA \& Shinsuke MORI. 2015. "A framework for procedural text understanding”. < http://www.aclweb.org/anthology/W15-2206>. Consulted 10/10/2018.

Michigan State University. 2007. "Biosystems Technical Writing Guide”, <https://msu-edu/ course/be/485/bewritingguideV2.pdf>. Consulted 03/03/2018.

Precision Science Editing. (Undated). "Use of light touch with the definite article". <http:// precisionscienceediting.com/tips/use-a-light-touch-with-the-definite-article/>. Consulted 03/03/2018.

RAMAKER, Sara. 2007. The Genre of Technical Manuals. Unpublished essay. Grand Valley State University. <ww2/gvsu.edu/chappesa/genre.doc>. Consulted 01/10/2018.

SAINT-DIZIER, Patrick, Estelle DELPECH, Asance KAWTRAKUL, Mukda SUKTARACHAN \& Patcharee VARASAI. 2014. "Annotating the facets of procedural texts". <https://www.researchgate.net/publication/ 228944696_Annotating_the_Facets_of_Procedural_Texts>.Consulted 15/10/2018.

SCHUMACHER, Helene. 2018. "Inside the world of instruction manuals". <http://www.bbc.com/ future/story/20180403-inside-the-world-of-instruction-manuals>. Consulted 03/10/2018.

SVENVOLD, Mark. 2015. “The disappearance of the instruction manual". Popular Science. Originally published under the title "Instructions not included". <https://www.popsci.com/instructionsnot-included>. Consulted 01/10/2018.

SWALES, John M. 1990. Genre Analysis: English in academic and research settings. Cambridge:

Cambridge University Press.

SWALES, John M. 1997. “The world's earliest-known technical texts: A brief note”. English for Specific Purposes 16/2, 151-153.

SWALES, John M. 2016. "Reflections on the concept of discourse community". ASp 69, 7-19. Also online: DOI: $10.4000 /$ asp.

SwipeGuide. <swipeguide.com>. Consulted 24/10/2018.

WEINBURGER, Cody J., James A. EVANS \& Stefano ALLESINA. 2015. "Ten simple empirical rules for writing science". PLOS. < doi.org./10.1371/journal.pcbi.1004205>. 


\section{NOTES}

1. Master de Traduction Spécialisée Multilingue (TSM), a 2-year programme offered by UGA (Université de Grenoble-Alpes) since 1992. Accredited by the European Commission, this programme carries an EMT label (European Master's in Translation).

2. Given the non-dematerialised nature of the texts and the qualitative approach of the study, we prefer the term "collection" to "corpus."

3. For information on the status of the language used for legally required information regarding products commercialised within the EU see Directive 2006/42/EC of the European Parliament and of the Council of 17 May 2006 on machinery and referred to as the Machinery Directive for short.

4. CE is the acronym for "Conformité Européenne" and used as such in the Directive 93/68/EEC. The CE logo on a product indicates the manufacturer declares the product complies with European health, safety and environmental requirements and may therefore be legally commercialised in the country.

5. This undoubtedly explains Kingscott's findings (2002: 247) that technical translation accounts for $90 \%$ of the world's total annual translation output.

6. Given the number of monolingual IFUs - and indeed, products sold with no IFUs at all - we must conclude that the law has not yet trickled down into practice.

7. E.g. in the case of Simplified Technical English (STE), the official controlled language for use in aerospace and defense industries, the word "close" must only be used as a verb as in "to close the door" or "to close a circuit." For the adverb, the approved word is "near." In other words, words are shorn of polysemous plurality.

8. 1. Make positive statements 2. Avoid long and complicated sentences 3 . Avoid too many subjects in one sentence 4. Avoid too many successive adjectives and nouns 5. Use uniform sentence structures 6. Avoid complicated past and future tenses 7. Avoid conditional sentences 8 . Avoid abbreviations, contractions, and colloquialisms 9. Use punctuation correctly 10. Use consistent nomenclature. (Crabbe, undated).

9. Invoking legal constraints, the ad does not divulge the salary. However, a French site (www.glassdoor.fr) cites the figure of an average salary at $68,893 \$ \mathrm{p} / \mathrm{a}$ for the position of a technical writer in the Washington State area. (October 2018). Although not an uncomfortable figure, it is evaluated at $-2 \%$ compared to the rest of the US.

10. A similar occurrence may be observed concerning the specialised genre of wine tasting notes (Isani 2017). The general consumer of wine - the presumed addressee - does not understand the specialised language of wine tasting notes. However, the notion of discourse community does become operable when applied to the writers of wine tasting notes who, behind the cover of writing for the consumer, are in fact engaged in a one-upmanship process of writing for their peers. This is obviously not the case with the technical writers of IFUs.

\section{ABSTRACTS}

This article posits that if the procedural subgenre Instructions for Use (IFU) qualifies as a specialised genre identifiable by characteristic textual and linguistic conventions, the corollary notion of discourse community is a moot question. After a brief overview of the umbrella genre of procedural texts and the extensive subgenre of IFUs, we look at the textual and linguistic features of the genre, notably with regard to its brachyology-imposed transgressive nature vis-à- 
vis Standard English, and its relation to controlled languages. We then discuss the notion of genre in relation to the Swalesian construct of discourse community. We examine the traits specific to the addresser (the technical writer) and conclude that a body of expert members does indeed exist. On the other hand, an analysis of the addressee (global end-users) in the light of the Kachruvian circles concludes that the shifting and ultra-diversified nature of the addressee's literacy and English language competence precludes their being grouped together as part of a homogeneous discourse community. To conclude we take a look at current trends towards wordless and dematerialised IFUs and hypothesise that the numerical divide will further disintegrate addressee cohesion.

Cet article postule que si le mode d'emploi peut être considéré comme genre spécialisé en raison de ses conventions textuelles et linguistiques, la notion corollaire de communauté discursive reste posée. Après un bref survol du genre procédural et du mode d'emploi en tant que sous-genre, nous examinons ses caractéristiques textuelles et linguistiques, notamment la concision syntaxique imposée par les exigences de brièveté. Nous nous intéressons aussi au mode d'emploi en tant qu'éventuel langage contrôlé. Nous étudions ensuite le mode d'emploi eu égard au concept de communauté discursive telle que définie par Swales, les caractéristiques $d u$ destinateur (le rédacteur technique) et du destinataire (le client final à l'échelle mondiale) pour conclure que le profil ultra-diversifié et fluctuant du destinateur en termes de compétence en anglais ne permet pas de l'envisager comme appartenant à une communauté discursive homogène. En conclusion, nous évoquons quelques évolutions du genre vers le remplacement de l'écrit par l'image et la dématérialisation du genre, des transformations qui ne feront que fragmenter davantage le peu de cohésion identitaire qui existe aujourd'hui au niveau des destinataires.

\section{INDEX}

Keywords: controlled languages, discourse community, instructions for use, procedural text, specialised genre, technical writing, user manual

Mots-clés: communauté discursive, genre spécialisé, langages contrôlés, manuel d'utilisation, mode d'emploi, rédaction technique, texte procédural

\section{AUTHOR}

\section{SHAEDA ISANI}

Shaeda Isani is Professor Emerita at the Foreign Languages Department (Université GrenobleAlpes, France). Her main research interests lie in English for Legal Purposes (terminology, culture, semiotics and fictional representations) but over the years she has also explored other specialisms such as the "sin" industries, oenology, ESP didactics and assessment. A number of her publications are available in open access online. shaeda.isani@univ-grenoble-alpes.fr 